\title{
Alcohol Consumption and the Risk of Nasopharyngeal Carcinoma: A Systematic Review
}

\author{
Liwei Chen, \\ Center for Human Nutrition, Department of International Health, Johns Hopkins University \\ Bloomberg School of Public Health, Baltimore, Maryland, USA \\ Lisa Gallicchio, \\ Prevention and Research Center, Weinberg Center for Women's Health and Medicine, Mercy \\ Medical Center, Baltimore, Maryland, USA \\ Kristina Boyd-Lindsley, \\ Department of Epidemiology, Johns Hopkins University Bloomberg School of Public Health, \\ Baltimore, Maryland, USA \\ Xuguang (Grant) Tao, \\ Division of Occupational and Environmental Medicine, Johns Hopkins University Bloomberg \\ School of Public Health, Baltimore, Maryland, USA
}

Karen A. Robinson,

Department of General Internal Medicine, Johns Hopkins University School of Medicine, Baltimore, Maryland, USA

Tram Kim Lam, Department of Epidemiology, Johns Hopkins University Bloomberg School of Public Health, Baltimore, Maryland, USA

James G. Herman, Department of Oncology, Johns Hopkins University School of Medicine, Baltimore, Maryland, USA

\section{Laura E. Caulfield,}

Center for Human Nutrition, Department of International Health, Johns Hopkins University Bloomberg School of Public Health, Baltimore, Maryland, USA

Eliseo Guallar, and Department of Epidemiology, Johns Hopkins University Bloomberg School of Public Health, Baltimore, Maryland, USA

\author{
Anthony J. Alberg \\ Hollings Cancer Center, Medical University of South Carolina, Charleston, USA
}

\footnotetext{
Copyright (C) 2009, Taylor \& Francis Group, LLC

Address correspondence to Anthony J. Alberg, Hollings Cancer Center, Medical University of South Carolina, 86 Jonathan Lucas Street, PO Box 250955, Charleston, SC 29425. Phone: 843-792-3246. Fax: 843-792-5526. alberg@ musc.edu.

Publisher's Disclaimer: Full terms and conditions of use: http://www.informaworld.com/terms-and-conditions-of-access.pdf This article may be used for research, teaching and private study purposes. Any substantial or systematic reproduction, re-distribution, re-selling, loan or sub-licensing, systematic supply or distribution in any form to anyone is expressly forbidden.

The publisher does not give any warranty express or implied or make any representation that the contents will be complete or accurate or up to date. The accuracy of any instructions, formulae and drug doses should be independently verified with primary sources. The publisher shall not be liable for any loss, actions, claims, proceedings, demand or costs or damages whatsoever or howsoever caused arising directly or indirectly in connection with or arising out of the use of this material.
} 


\section{Abstract}

The evidence concerning the influence of alcohol drinking on the risk of nasopharyngeal carcinoma (NPC) has yielded intriguing findings but has lacked a clear-cut interpretation due to inconsistencies. To unify this body of evidence, we performed a systematic review. With funding and using a protocol developed by the World Cancer Research Fund (WCRF), 15 bibliographic databases were searched for epidemiological studies that reported a measure of association between alcoholic beverage consumption and NPC. Pooled odds ratios (ORs) for highest-vs.lowest categories of total alcohol intake was obtained by using an inverse-variance weighted random-effects model. A dose-response trend was examined in models using generalized least square estimation. The search identified 14 case-control studies from 5 countries. For total alcohol intake, the pooled ORs in a comparison of the highest to the lowest category was 1.33 (95\% CI: $=$ 1.09-1.62) in 11 studies. Data from 6 studies indicated a J-shape dose-response trend, with NPC risk decreasing with up to 15 drinks/wk and increasing with higher intake. Fewer data were available to assess the associations between NPC and intake of beer, wine, and spirits. The potential J-shaped dose-response trend suggests a reduced risk of NPC related to the light alcohol drinking, an observation that warrants further study. Considered in total, the quantitative summaries of the case-control evidence suggest that heavy alcohol consumption is associated with an increased risk of NPC.

\section{INTRODUCTION}

Nasopharyngeal carcinoma (NPC) has a unique geographic pattern of occurrence. Although rare in most regions (worldwide rates of 1.7 and 0.6 per 100,000 among men and women, respectively), NPC has high incidence rates in a few specific populations such as Hong Kong and southern China (age-adjusted incidence rates of 25 to 30 per 100,000) (1). In 2002, NPC was the fourth most common cancer in Hong Kong compared to the 23rd most common cancer in the world (2).

An important step to prevent NPC is to identify and understand factors that contribute to this large discrepancy in NPC rates, but only limited progress has been achieved. Early-life infection with the Epstein-Barr virus (EBV) may be a critical etiological factor for development of NPC. However, a large proportion of individuals worldwide are infected with the virus, but only a small proportion of them develop NPC. It thus seems likely that genetic and/or environmental triggers play an important role in NPC carcinogenesis. Part of the striking variation in NPC rates may be due to dietary and lifestyle factors. The consumption of Cantonese-style salted fish (3-8) and the consumption of many preserved foods have been related to increased risk of NPC $(5,8-11)$. However, Cantonese-style salted fish and other preserved foods are not frequently consumed in many communities with high or intermediate incidence (12). Therefore, to achieve a better understanding of NPC pathogenesis, other dietary and lifestyle factors need to be considered.

Additional possible risk factors for NPC are tobacco and alcohol use (12-14). The majority of case-control studies examining the association of cigarette smoking and NPC risk reported twofold to fourfold increases in risk (15-22). In contrast, studies examining the association between alcohol consumption and NPC risk are inconsistent $(10,18,20,36-39)$. It is possible that alcohol drinking does not contribute to NPC risk, but other potential reasons for the inconsistencies are differences in study design, geographic location, measurement methods for alcohol intake, and adjustment of other risk factors for NPC across studies. Because no systematic reviews have been conducted to summarize this body of evidence, the purpose of this study was to systematically review the current epidemiological evidence on the association between alcohol consumption and the risk of NPC. 


\section{MATERIALS AND METHODS}

This study was conducted as a part of a project entitled "Food, Nutrition, Physical Activity and the Prevention of Cancer: a Global Perspective," which was funded by the World Cancer Research Fund (WCRF) and the American Institute for Cancer Research (AICR). All of the work (including this study) funded under this project was conducted using a WCRF standardized protocol (http://www.wcrf.org/research/secondwcrf_aicr_report.lasso). However, the conclusions of this study may differ from those in the WCRF's report because the WCRF applied different evaluation criteria in their report.

\section{Literature Search}

For the WCRF report, all evidence relating to food, nutrition, physical activity, and NPC reported in randomized clinical trials and observational studies was searched by using the search strategy previously described (11). Briefly, there were 3 steps in applying the search strategy: 1) electronic searches of 14 non-Chinese bibliographic databases including PubMed, Embase, and the Cochrane Library; 2) electronic searches of the Chinese Biomedical Literature Database System (in Chinese); and 3) hand searching of the references cited in the 1997 WCRF report (23), in the articles chosen for data abstraction, and in relevant review articles or meta-analyses identified in the PubMed search. There were no language restrictions in our searches. These 3 steps resulted in the identification of 3,225 potentially relevant unique articles that were published by April 2006.

\section{Study Selection}

The following exclusion criteria were applied to both abstracts and full text articles: 1) no original data (reviews, editorials, meta-analyses); 2) studies not addressing the association between food, nutrition, physical activity and NPC risk; 3) studies not in humans; and 4) case reports and case series. Full-text articles were obtained for all eligible abstracts and for those whose eligibility was unclear. The eligibility of abstracts and full-text articles was evaluated independently by two reviewers using the same protocol. Disagreements between reviewers were resolved by consensus.

To be included in this systematic review, the studies had to 1) address the association between alcohol intake (total alcohol, beer, wine, spirits, or any alcoholic beverages) and NPC risk, 2) measure the association at the individual level, and 3) report measures of association or provide enough detail so that the measure of association could be calculated from the data provided. If separate articles from the same study were published, the article with the most updated data was selected for use in this study. In the case of duplicate publication, only one publication was included.

\section{Data Extraction}

Data were extracted from the eligible articles by two reviewers using an electronic abstraction database created by WCRF. The protocol for data extraction has been described previously (11). Data were extracted for total alcohol drinks and for beer, wine, spirits, and other alcohol drinks. During data extraction, we collected all quantitative results reported for alcohol intake including intake measured as a dichotomous variable (alcohol drinking yes/ no) as well as any type of dose assessment. Information on duration of alcohol drinking was also extracted. The doses of alcohol intake were converted to the number of drinks per week in our analyses to provide uniform comparisons across studies. In this review, one drink was defined as $13.7 \mathrm{~g}$ of ethanol (http://www.cdc.gov/alcohol/faqs.htm), which is equivalent to $355 \mathrm{ml}(12 \mathrm{oz})$ of beer, $148 \mathrm{ml}(5 \mathrm{oz})$ of wine, or $44 \mathrm{ml}(1.3 \mathrm{oz})$ of spirits. 
Study quality was evaluated according to a modification of the criteria used by Longnecker et al. (24) to assess the quality of studies of the association of alcohol intake and breast cancer.

\section{Statistical Analysis}

Separate analyses were carried out for the 4 major categories of alcohol consumption: 1) total alcohol, 2) beer, 3) wine, and 4) spirits (liquor). We estimated the pooled odds ratios (ORs) and 95\% confidence intervals (CI) comparing the risk for NPC in the highest-vs.lowest alcohol intake category reported in each study by using inverse-variance weights in random effects models. Statistical heterogeneity was assessed using the DerSimonian and Laird's Q statistic and $\mathrm{I}^{2}$ statistic $\left(\mathrm{I}^{2}>50 \%\right.$ was considered a meaningful level of heterogeneity). The $\mathrm{Q}$ test provides information about the presence or the absence of between-study heterogeneity, whereas the $\mathrm{I}^{2}$ statistic quantifies the degree of heterogeneity and is interpretable as the percentage of the total association that may be due to heterogeneity between studies. Sensitivity analyses to examine the influence of each individual study were conducted by excluding each study from the meta-analysis and comparing the point estimates including and excluding the study. Publication bias was examined using funnel plots.

A meta-regression analysis was conduced to explore the sources of statistical heterogeneity in the meta-analyses. Variables included in the analysis were country of study (China/other), number of cases ( $<150$ and $\geq 150$ ), source of controls (population/hospital), statistical adjustment for smoking and/or salted fish, and histological confirmation of cases (yes-no). Subgroup analyses were conducted by stratifying the analysis according to studies that did and did not adjust for cigarette smoking and according to country.

A random-effects, dose-response meta-analysis was conducted with studies that reported $\geq 3$ categories of exposure by using the generalized least square estimation and "pool-first" methods (25). To fully explore the possible relationship between alcohol intake and risk of NPC, both linear and quadratic models were applied to fit the trend of the dose response. All analyses were conducted by using STATA 9.0 (Stata Corporation, College Station, TX) and $\mathrm{R}$ (a free statistical software supported by the R Foundation).

\section{RESULTS}

\section{Search Results}

The search of literature on dietary intake and NPC yielded 3,225 references (Fig. 1). Of these references, 3,149 were excluded after abstract or full-text review. Of the 76 articles that were obtained for full-text review, 22 articles were relevant to alcohol intake and NPC risk. Of these 22 articles, we excluded two that did not measure alcohol intake at the individual level $(26,27)$, two that presented data already reported in other publications $(28,29)$, and $4(8,15,30,31)$ that only reported in the text that the results were not statistically significant. These latter studies provided no numeric data whatsoever. Fourteen studies $(7,10,16,18,20,22,32-39)$ met the inclusion criteria and were included in this systematic review. Of these, 11 studies addressed the relationship between total alcohol intake and NPC risk and were included in the primary meta-analyses.

\section{Study Characteristics}

All studies included in the meta-analysis used a case-control design (Table 1). They were published between 1976 and 2001; only one study was published in a Chinese language journal (38). The number of cases ranged across the studies from 39 (16) to 935 (37). Five studies had 150 cases or less $(7,16,33,36,38)$. The source of controls was population based in 
9 studies $(10,18,20,22,32,35-38)$ and hospital based in 5 studies $(7,16,33,34,39)$. Eight studies (10,20,32-34,36-38) were conducted among Chinese residents of Asian countries or regions (three in mainland China, two in Taiwan, two in Malaysia, and one in Singapore), five in the United States $(16,18,22,35,39)$, and one among Thai in Thailand (7).

Six studies measured $(7,16,33,34,38,39)$ the alcohol intake as a dichotomous variables (yes or no); 6 studies $(10,18,22,35-37)$ reported the alcohol consumption frequency data and had 3 or more consumption categories. Two studies $(20,32)$ reported duration of alcohol intake in years, and one study (20) reported lifetime cumulative alcohol consumption $(\mathrm{g} \times \mathrm{yr})$.

\section{Quality Assessment}

Most of the 14 case-control studies lacked information on the specifics of data collection for cases and controls including whether data were collected in a similar manner for all study participants and whether interviewers were blinded to the case status of the participants. Although all but one (18) of the studies analyzed included incident cases of NPC, only one (37) explicitly stated that cases were interviewed within 6 mo of diagnosis. Seven studies $(7,20,22,32,35-37)$ mentioned that alcohol intake information was collected using a structured or validated questionnaire (details of the questionnaire were not specified). Details on how one alcohol drink was defined (based on the ethanol content of beverages) were reported in only one study (37). Nine studies stated that the NPC cases were histologically confirmed $\left(7,10,16,20,{ }^{22}, 32,34,36,37\right)$, and 5 studies $(10,20,22,36,37)$ reported response rates in both cases and controls. Only 4 studies adjusted for smoking $(18,20,22,37)$, two adjusted for both smoking and salted fish $(7,38)$, and none adjusted for EBV (Table 2). The large number of "NAs" (not available) in Table 2 provides evidence about the generally poor quality of the studies.

\section{Total Alcohol Intake and NPC Risk}

Eleven case-control studies evaluated the association of total alcohol intake with NPC risk (Table 3). Of these 11 studies, 4 only reported $(7,16,33,38)$ the alcohol intake as a dichotomous (yes or no) variable. The pooled OR was 1.33 (95\% CI = 1.09-1.62; Fig. 2), with no evidence of statistically significant heterogeneity $(P$ for heterogeneity of $\mathrm{Q}$ test $=$ $0.28 ; \mathrm{I}^{2}=17.1 \%$ ). The funnel plot did not suggest the presence of publication bias. In sensitivity analyses, exclusion of individual studies did not change the estimate substantially, with pooled ORs ranging from 1.25 to 1.40.

Meta-regression and subgroup analyses showed that the study population and adjustment for smoking had statistically significant influence on the heterogeneity. The pooled OR for the highest-vs.-lowest category comparison was $1.26(95 \% \mathrm{CI}=0.99-1.62)$ in studies controlling for smoking compared to $1.47(95 \% \mathrm{CI}=1.02-2.12)$ for studies not controlling for smoking. The association was weaker in Chinese (pooled OR $=1.21 ; 95 \% \mathrm{CI}=0.98$ 1.62) than in U.S. (pooled $\mathrm{OR}=1.50 ; 95 \% \mathrm{CI}=1.08-2.10$ ) populations.

The advantage of the highest-vs.-lowest category comparison is that it allows inclusion of the maximum number of studies. In interpreting the results of this approach, however, one ought to bear in mind that the classification of alcohol drinking in the highest category varies considerably across the 11 studies included, from drinking any alcohol to drinking $\geq 31$ drinks/wk (Table 3). This heterogeneity of exposure definitions may impact the estimated association between alcohol drinking and NPC. To address this, we performed analyses stratified according to whether studies were limited to a simple dichotomous comparison ( $n=4$ studies) or had 3 or more categories ( $n=7$ studies). The results revealed heterogeneity across strata, with an OR of $1.15(95 \% \mathrm{CI}=0.82-1.62)$ in studies limited to 
dichotomous comparisons and an OR of $1.45(95 \% \mathrm{CI}=1.12-1.87)$ in studies with 3 or more categories.

In a more refined analysis of the association between alcohol drinking and NPC, we conducted a dose-response meta-analysis with models that tested for both linear and quadratic trends. Six studies $(18,22,34-37)$ that reported $\geq 3$ categories of the frequency of total alcohol intake were included in our dose-response meta-analysis. The best-fitting model showed a "J-shaped" dose-response curve $(P$ value for quadratic term $=0.005)$ with NPC risk decreasing up to 15 drinks/wk (OR comparing 15 to 0 drinks $/ w k=0.82$ ) and increasing with higher intake (OR comparing 30 to 0 drinks/wk =1.12) (Fig. 3).

Two studies $(20,32)$ also evaluated the association between the duration of alcohol intake and NPC risk among Chinese. In the study of Chen et al. (32), the OR for NPC comparing more than $30 \mathrm{yr}$ of consumption to nonconsumption was 1.84 (95\% CI $=0.97-3.47)$. In the study of Cheng et al. (20), the OR for NPC comparing more than $15 \mathrm{yr}$ of consumption to less than $15 \mathrm{yr}$ was $1.1(95 \% \mathrm{CI}=0.7-1.6)$; and the OR for NPC comparing individuals with life-time cumulative alcohol consumption equal or greater than $500 \mathrm{~g} / \mathrm{yr}$ to nondrinkers was $1.2(95 \% \mathrm{CI}=0.7-2.2)$.

\section{Intake of Beer, Wine, Spirits, and Other Alcoholic Beverages and NPC Risk}

Studies that have investigated the type-specific alcohol intake and NPC risk are limited, and results are mixed. Beer drinking was positively associated with NPC risk in a study conducted among Chinese in Malaysia (10), but not in 2 studies $(16,39)$ conducted in the United States (Table 4). The pooled OR for these 3 studies comparing the highest-vs.-lowest beer intake categories was $1.32(95 \% \mathrm{CI}=0.69-2.52)$. The above 3 studies also assessed the association between spirits intake and NPC risk. As with the results for beer intake, the result of a study (10) in Malaysia showed a strong association with NPC, whereas the U.S. studies did not find a positive association. The pooled OR comparing the highest-vs.-lowest category of spirits intake was $1.09(95 \% \mathrm{CI}=0.43-2.77)$. The two studies carried out in the United States also reported on the association between wine intake and NPC risk $(16,39)$. The unadjusted OR was 0.58 (95\% CI $=0.23-1.46)$ in the study of Mabuchi (16) and 0.7 (95\% CI: $0.49,0.992)$ in the study of Henderson et al. (39). In the lone study to assess the association between NPC risk and Chinese rice wine (made from millets, it has an alcohol content of 14-20\%), carried out in Hong Kong (33), a significant inverse association with NPC risk was observed $(\mathrm{OR}=0.56 ; 95 \% \mathrm{CI}=0.35-0.90)$.

\section{DISCUSSION}

In this systematic review, there was a 33\% increased in risk of NPC comparing the highest category of total alcohol intake to the lowest category across 11 case-control studies included in the pooled analysis. In more detailed dose-response analyses using data from 6 case-control studies with 3 or more categories of alcohol exposure, we identified a $\mathbf{J}$-shaped relationship, with a nadir of NPC risk at approximately 15 drinks/wk and an increased risk with respect to nondrinkers above $28-30$ drinks/wk (4 drinks/day). This complex doseresponse relationship has not been identified previously, and it deserves further investigation. If confirmed, it could explain some of the inconsistencies observed in previous studies.

Two studies that did not qualify for our meta-analysis deserve further comment. A cohort study published after the closeout date of our literature search examined the relationship between cigarette smoking, alcohol intake, and NPC risk among Chinese in Singapore (40). Compared with nondrinkers, the relative risk was $0.9(95 \% \mathrm{CI}=0.6-1.4)$ for individuals with alcohol intake between $1-7$ drinks/wk and $1.3(95 \% \mathrm{CI}=0.8-2.3)$ for those with 
alcohol intake more than 7 drinks/wk after adjustment of age, sex, level of education, smoking, and intake of protein-rich preserved foods and fresh vegetables. Although not statistically significant, perhaps due to the lack of precision from the low prevalence of alcohol drinking, the results of this cohort study are consistent with the overall findings observed in our systematic review. In this cohort study of Chinese in Singapore, there was no interaction between smoking and alcohol intake on NPC risk. Another cohort study conducted in Sweden (27) followed 182,667 patients with a hospital discharge diagnosis of alcoholism for an average of $10.2 \mathrm{yr}$ and compared their incidence of NPC with national incidence data. The standardized incidence ratio was 1.56 (95\% CI $=0.97-2.39)$. However, alcohol intake was not measured, and other risk factors and potential confounders were not controlled for in this study. Overall, these two studies support our finding of a modestly increased risk of NPC with high alcohol intake.

Our finding of an increased NPC risk with high alcohol intake is biologically plausible and consistent with well-established positive associations of alcohol intake with increased risk for other upper aerodigestive cancers. Ethanol has been thought to be the key compound responsible for the effect of alcoholic beverages consumption on cancer (41). Multiple mechanisms have been proposed to contribute to the ethanol-associated cancer development. Acetaldehyde, an oxidation product of alcohol, is known to be toxic, carcinogenic, and mutagenic. In experimental and animal studies, acetaldehyde interferes at many sites with DNA synthesis and repair and can result in tumor development (42-44). Chronic alcohol consumption also induces cytochrome P450 enzyme (CYP2E1) activity in mucosal cells (43). Induction of CYP2E1 can lead to stimulation of free radical formation and thus cause cell injury. In addition, heavy and chronic alcohol intake may result in various deficiencies of vitamins and trace elements, including folate, iron, zinc, and vitamin A, involved in gene regulation and cell differentiation. Therefore, nutritional deficiencies commonly observed in heavy drinkers may further enhance ethanol-associated carcinogenesis (43).

Although a substantial body of biological and epidemiological evidence can support a positive association of high alcohol intake with cancer risk, the interpretation of an inverse association between low-dose alcohol intake and NPC is challenging. Many studies from different countries have consistently shown J- or U-shaped dose-response relationships between alcohol intake and cardiovascular disease $(49,50)$ and all cause mortality $(51-57)$. The presumed beneficial effect of low-dose alcohol intake on CVD may be due to elevations of plasma high-density lipoprotein cholesterol or reductions of platelet aggregation (58-60). In contrast, most previous data of alcohol intake and cancer endpoints supported monotonic increases with increasing alcohol intake (61), and reports of a possible benefit of light-tomoderate alcohol intake on cancer have been rare. The 6 case control studies included in our dose-response meta-analysis, however, showed lower risk at intermediate alcohol intake categories compared to no intake or higher intake. It is unclear what biological mechanism could explain this effect. Wine contains a relatively high concentration of polyphenols (mostly flavonoids and resveratrol) with potential antioxidant and chemopreventive activities that could inhibit initiation, promotion, and progression of cancer (45-48). Few data were available to examine the association between risk of NPC and specific types of alcohol even though two studies had observed a reduced NPC risk with wine consumption. It is also possible that other lifestyle factors related with light-to-moderate alcohol intake may contribute to the observed inverse association. Much remains to be learned about this association, and further studies are needed to confirm this finding.

In our meta-analysis, alcohol intake was associated with increased risk in both U.S. and Chinese populations, but the association was stronger and statistically significant in the U.S. studies. We can only speculate on potential explanations. Alcohol intake is lower in Chinese populations compared to Western populations $(37,62,63)$, so it is possible that studies in 
Chinese reflected populations drinking at a level that may not be so detrimental for NPC development. Second, the difference in histological type of NPC may also play a role. NPC can be classified into 3 histological types: keratinizing squamous cell carcinoma (or differentiated carcinoma, type 1), nonkeratinizing carcinoma (type 2), and undifferentiated carcinoma UCNT (type 3) (64). The undifferentiated and nonkeratinizing carcinomas are the major forms of NPC identified in the high-risk regions such as China and other parts of Asia, whereas the keratinizing squamous cell carcinoma is identified in one-third to one-half of the NPC cases occurring in low-risk populations, such as North Americans (65). There is evidence that heavy alcohol consumption may be a risk factor for differentiated squamous cell cancer but not undifferentiated and nonkeratinizing squamous cell carcinomas. In the study of Vaughan et al. in 1996 (22), when individuals who drank >21 drinks/wk were compared to those who drink 0-6 drinks/wk, the results were statistically significant $(\mathrm{OR}=$ $2.9 ; 95 \% \mathrm{CI}=1.2-6.9)$ among the differentiated NPC cases but not among the undifferentiated and nonkeratinizing NPC cases $(\mathrm{OR}=1.3 ; 95 \% \mathrm{CI}=0.3-5.1)$. In the United States, a large proportion of NPC cases are differentiated carcinomas for which the associations between alcohol drinking and NPC would be expected to be the strongest. This issue remains to be thoroughly investigated, as most of the studies ascertained in this systematic review did not provide information regarding the histological type of NPC. Finally, the epidemiology of childhood EBV infection is different in Chinese and in Western populations $(66,67)$, and the effect of alcohol could be different depending on the timing of EBV infection.

The evidence included in our systematic review suffers from several limitations. All studies included in this meta-analysis used a case-control design, although a recent cohort study in Singapore had similar results (40). The methodological quality of many of these studies was limited, and certain biases or confounding factors may have not been accounted for in the original studies. As a major risk factor, EBV infection was not addressed in any study. Another important risk factor for NPC, intake of salted fish, was controlled for in only two studies. Because alcohol intake is correlated with smoking and because smoking is a risk factor for NPC, confounding by smoking is a major concern. When we restricted our metaanalysis to studies that controlled for smoking in their original analyses, the pooled OR was slightly attenuated and borderline significant (OR comparing the highest vs. the lowest category of alcohol intake $=1.26 ; 95 \% \mathrm{CI}=0.99-1.62$ ). Although there is potential for residual confounding, previous findings of a statistically significant association between alcohol intake and NPC risk among former and never smokers (22) implies that alcohol may be an independent risk factor for NPC. A recent study (68) also observed that never users of tobacco who consumed 3 or 4 more alcoholic drinks per day had approximately twice the risk of head and neck cancer as never drinkers $(\mathrm{OR}=2.04 ; 95 \% \mathrm{CI}=1.29-3.21)$, which indicates that alcohol drinking could be an independent risk factor for head and neck malignancies including NPC. Additionally, most studies had provided few details on precisely how they measured alcohol consumption. Only 7 studies mentioned that alcohol intake information was collected using a structured or validated questionnaire. Publication bias was not evident in the funnel plots. However, publication bias may still be of concern because there were 4 case-control studies that only reported in the text that the association between alcohol drinking and NPC was not statistically significant. In these 4 reports, no numeric data were presented, leaving these studies to be excluded from our meta-analyses. To the extent that the results of these studies were actually consistent with a null association (rather than an association in the direction of increased risk that was not statistically significant), the results of our meta-analyses may overestimate the positive association of alcohol intake and NPC risk. To achieve a more complete understanding of this topic, it will be valuable for future studies to quantify the association between alcohol drinking and NPC as completely as possible. Finally, we note that the methodological limitations discussed 
here could explain the association of high alcohol intake with NPC risk but are unlikely to explain the inverse association observed at low intake levels.

In summary, we identified a J-shaped relationship between alcohol intake and NPC risk. The pattern of inverse association at low levels of alcohol intake is unusual for cancer endpoints and deserves further consideration in prospective studies, with careful control for potential confounders and with detailed evaluation of the impact of different types of alcoholic drinks. The positive association between high alcohol intake and NPC risk is consistent with the effect of alcohol on other cancers in the upper aerodigestive track and adds to the extensive evidence base to avoid excessive alcohol consumption.

\section{Acknowledgments}

This research was made possible through the support of the World Cancer Research Fund. Sources of additional support were the U.S. National Institute of Aging (5U01AG018033) and the National Cancer Institute (CA105069, 5U01CA086308).

\section{REFERENCES}

1. GLOBOCAN 2000: Cancer Incidence, Mortality and Prevalence Worldwide. Version 1.0. Lyon, France: IARC Press; 2001.

2. Parkin DM, Bray F, Ferlay J, Pisani P. Estimating the world cancer burden: Globocan 2000. Int J Cancer. 2001; 94:153-156. [PubMed: 11668491]

3. Yu MC, Ho JH, Ross RK, Henderson BE. Nasopharyngeal carcinoma in Chinese-salted fish or inhaled smoke? Prev Med. 1981; 10:15-24. [PubMed: 7232343]

4. Yu MC, Ho JH, Lai SH, Henderson BE. Cantonese-style salted fish as a cause of nasopharyngeal carcinoma: report of a case-control study in Hong Kong. Cancer Res. 1986; 46:956-961. [PubMed: 3940655]

5. Yu MC, Mo CC, Chong WX, Yeh FS, Henderson BE. Preserved foods and nasopharyngeal carcinoma: a case-control study in Guangxi, China. Cancer Res. 1988; 48:1954-1959. [PubMed: 3349469]

6. Yu MC, Huang TB, Henderson BE. Diet and nasopharyngeal carcinoma: a case-control study in Guangzhou, China. Int J Cancer. 1989; 43:1077-1082. [PubMed: 2732001]

7. Sriamporn S, Vatanasapt V, Pisani P, Yongchaiyudha S, Rungpitarangsri V. Environmental risk factors for nasopharyngeal carcinoma: a case-control study in northeastern Thailand. Cancer Epidemiol Biomarkers Prev. 1992; 1:345-348. [PubMed: 1305465]

8. Ning JP, Yu MC, Wang QS, Henderson BE. Consumption of salted fish and other risk factors for nasopharyngeal carcinoma (NPC) in Tianjin, a low-risk region for NPC in the People's Republic of China. J Natl Cancer Inst. 1990; 82:291-296. [PubMed: 2299678]

9. Lee HP, Gourley L, Duffy SW, Esteve J, Lee J, et al. Preserved foods and nasopharyngeal carcinoma: a case-control study among Singapore Chinese. Int J Cancer. 1994; 59:585-590. [PubMed: 7960230]

10. Armstrong RW, Imrey PB, Lye MS, Armstrong MJ, Yu MC, et al. Nasopharyngeal carcinoma in Malaysian Chinese: salted fish and other dietary exposures. Int J Cancer. 1998; 77:228-235. [PubMed: 9650558]

11. Gallicchio L, Matanoski G, Tao XG, et al. Adulthood consumption of preserved and nonpreserved vegetables and the risk of nasopharyngeal carcinoma: a systematic review. Int J Cancer. 2006; 119:1125-1135. [PubMed: 16570274]

12. Yu MC, Yuan JM. Epidemiology of nasopharyngeal carcinoma. Semin Cancer Biol. 2002; 12:421429. [PubMed: 12450728]

13. Seitz HK, Stickel F, Homann N. Pathogenetic mechanisms of upper aerodigestive tract cancer in alcoholics. Int J Cancer. 2004; 108:483-487. [PubMed: 14696110]

14. Chang ET, Adami HO. The enigmatic epidemiology of nasopharyngeal carcinoma. Cancer Epidemiol Biomarkers Prev. 2006; 15:1765-1777. [PubMed: 17035381] 
15. Lin TM, Chen KP, Lin CC, Hsu MM, Tu SM, et al. Retrospective study on nasopharyngeal carcinoma. J Natl Cancer Inst. 1973; 51:1403-1408. [PubMed: 4762926]

16. Mabuchi K, Bross DS, Kessler II. Cigarette smoking and nasopharyngeal carcinoma. Cancer. 1985; 55:2874-2876. [PubMed: 3995493]

17. Yu MC, Garabrant DH, Huang TB, Henderson BE. Occupational and other non-dietary risk factors for nasopharyngeal carcinoma in Guangzhou, China. Int J Cancer. 1990; 45:1033-1039. [PubMed: 2351484]

18. Nam JM, McLaughlin JK, Blot WJ. Cigarette smoking, alcohol, and nasopharyngeal carcinoma: a case-control study among U.S. whites. J Natl Cancer Inst. 1992; 84:619-622. [PubMed: 1556772]

19. Chow WH, McLaughlin JK, Hrubec Z, Nam JM, Blot WJ. Tobacco use and nasopharyngeal carcinoma in a cohort of US veterans. Int J Cancer. 1993; 55:538-540. [PubMed: 8406978]

20. Cheng YJ, Hildesheim A, Hsu MM, Chin IH, Brinton LA, et al. Cigarette smoking, alcohol consumption and risk of nasopharyngeal carcinoma in Taiwan. Cancer Causes Control. 1999; 10:201-207. [PubMed: 10454065]

21. Armstrong RW, Imrey PB, Lye MS, Armstrong MJ, Yu MC, et al. Nasopharyngeal carcinoma in Malaysian Chinese: occupational exposures to particles, formaldehyde and heat. Int J Epidemiol. 2000; 29:991-998. [PubMed: 11101539]

22. Vaughan TL, Shapiro JA, Burt RD, et al. Nasopharyngeal cancer in a low-risk population: defining risk factors by histological type. Cancer Epidemiol Biomarkers Prev. 1996; 5:587-593. [PubMed: 8824359]

23. World Cancer Fund (WCRF) and the American Institute for Cancer Research (AICR). Food, nutrition, and the prevention of cancer: a global perspective. Washington, DC: WRCF and AICR; 1997.

24. Longnecker MP, Berlin JA, Orza MJ, Chalmers TC. A meta-analysis of alcohol consumption in relation to risk of breast cancer. JAMA. 1988; 260:652-656. [PubMed: 3392790]

25. Greenland S, Longnecker MP. Methods for trend estimation from summarized dose-response data, with applications to meta-analysis. Am J Epidemiol. 1992; 135:1301-1309. [PubMed: 1626547]

26. Longnecker MP, Wolz M, Parker DA. Ethnicity, distilled spirits consumption and mortality in Pennsylvania. J Stud Alcohol. 1981; 42:791-796. [PubMed: 7311538]

27. Boffetta P, Ye W, Adami HO, Mucci LA, Nyren O. Risk of cancers of the lung, head and neck in patients hospitalized for alcoholism in Sweden. Br J Cancer. 2001; 85:678-682. [PubMed: 11531251]

28. Nazar-Stewart V, Vaughan TL, Burt RD, Chen C, Berwick M, et al. Glutathione S-transferase M1 and susceptibility to nasopharyngeal carcinoma. Cancer Epidemiol Biomarkers Prev. 1999; 8:547551. [PubMed: 10385146]

29. Hildesheim A, Anderson LM, Chen CJ, Cheng YJ, Brinton LA, et al. CYP2E1 genetic polymorphisms and risk of nasopharyngeal carcinoma in Taiwan. J Natl Cancer Inst. 1997; 89:1207-1212. [PubMed: 9274915]

30. Zheng YM, Tuppin P, Hubert A, Jeannel D, Pan YJ, et al. Environmental and dietary risk factors for nasopharyngeal carcinoma: a case-control study in Zangwu County, Guangxi, China. Br J Cancer. 1994; 69:508-514. [PubMed: 8123482]

31. Zheng X, Yan L, Nilsson B, Eklund G, Drettner B. Epstein-Barr virus infection, salted fish and nasopharyngeal carcinoma: a case-control study in southern China. Acta Oncol. 1994; 33:867872. [PubMed: 7818917]

32. Chen CJ, Liang KY, Chang YS, et al. Multiple risk factors of nasopharyngeal carcinoma: EpsteinBarr virus, malarial infection, cigarette smoking and familial tendency. Anticancer Res. 1990; 10:547-553. [PubMed: 2161639]

33. Geser A, Charnay N, Day NE, de-The G, Ho HC. Environmental factors in the etiology of nasopharyngeal carcinoma: report on a case-control study in Hong Kong. IARC Sci Publ. 1978; 20:213-229. [PubMed: 730191]

34. Shanmugaratnam K, Tye CY, Goh EH, Chia KB. Etiological factors in nasopharyngeal carcinoma: a hospital-based, retrospective, case-control, questionnaire study. IARC Sci Publ. 1978; 20:199_ 212. [PubMed: 730190] 
35. Vaughan TL. Occupation and squamous cell cancers of the pharynx and sinonasal cavity. Am J Ind Med. 1989; 16:493-510. [PubMed: 2589327]

36. Yu MC, Ho JH, Henderson BE, Armstrong RW. Epidemiology of nasopharyngeal carcinoma in Malaysia and Hong Kong. Natl Cancer Inst Monogr. 1985; 69:203-207. [PubMed: 3834333]

37. Yuan JM, Wang XL, Xiang YB, Gao YT, Ross RK, et al. Non-dietary risk factors for nasopharyngeal carcinoma in Shanghai, China. Int J Cancer. 2000; 85:364-369. [PubMed: 10652428]

38. Zou JM, Sun QF, Yuan YL, Qiu YCB, Zha YR, et al. A case-control study of nasopharyngeal carcinoma among inhabitants in high background radiation areas of Yangjiang, China. Chin J Radiol Med Prot. 1999; 19:90-94.

39. Henderson BE, Louie E, SooHoo Jing J, Buell P, Gardner MB. Risk factors associated with nasopharyngeal carcinoma. N Engl J Med. 1976; 295:1101-1106. [PubMed: 980005]

40. Friborg JT, Yuan JM, Wang R, Koh WP, Lee HP, et al. A prospective study of tobacco and alcohol use as risk factors for pharyngeal carcinomas in Singapore Chinese. Cancer. 2007; 109:11831091. [PubMed: 17315158]

41. Seitz HK, Poschl G, Simanowski UA. Alcohol and cancer. Recent Dev Alcohol. 1998; 14:67-95. [PubMed: 9751943]

42. Seitz HK, Garro AJ, Lieber CS. Enhanced pulmonary and intestinal activation of procarcinogens and mutagens after chronic ethanol consumption in the rat. Eur J Clin Invest. 1981; 11:33-38. [PubMed: 6783427]

43. Poschl G, Seitz HK. Alcohol and cancer. Alcohol. 2004; 39:155-165.

44. Yokoyama A, Omori T. Genetic polymorphisms of alcohol and aldehyde dehydrogenases and risk for esophageal and head and neck cancers. Jpn J Clin Oncol. 2003; 33:111-121. [PubMed: 12672787]

45. Jang M, Cai L, Udeani GO, Slowing KV, Thomas CF, et al. Cancer chemopreventive activity of resveratrol, a natural product derived from grapes. Science. 1997; 275:218-220. [PubMed: 8985016]

46. Kampa M, Hatzoglou A, Notas G, Damianaki A, Bakogeorgu E, et al. Wine antioxidant polyphenols inhibit the proliferation of human prostate cancer cell lines. Nutr Cancer. 2000; 37:223-233. [PubMed: 11142097]

47. Yang CS, Landau JM, Huang MT, Newmark HL. Inhibition of carcinogenesis by dietary polyphenolic compounds. Annu Rev Nutr. 2001; 21:381-406. [PubMed: 11375442]

48. Delmas D, Lancon A, Colin D, Jannin B, Latruffe N. Resveratrol as a chemopreventive agent: a promising molecule for fighting cancer. Curr Drug Targets. 2006; 7:423-442. [PubMed: 16611030]

49. Kiechl S, Willeit J, Rungger G, Egger G, Oberhollenzer F, et al. Alcohol consumption and atherosclerosis: what is the relation? Prospective results from the Bruneck Study. Stroke. 1998; 29:900-907. [PubMed: 9596232]

50. Kitamura A, Iso H, Sankai T, Naito Y, Sato S, et al. Alcohol intake and premature coronary heart disease in urban Japanese men. Am J Epidemiol. 1998; 147:59-65. [PubMed: 9440399]

51. Farchi G, Fidanza F, Mariotti S, Menotti A. Alcohol and mortality in the Italian rural cohorts of the Seven Countries Study. Int J Epidemiol. 1992; 21:74-81. [PubMed: 1544762]

52. Gronbaek M, Deis A, Sorensen TI, Becker U, Borch-Johnson K, et al. Influence of sex, age, body mass index, and smoking on alcohol intake and mortality. BMJ. 1994; 308:302-306. [PubMed: 8124118]

53. Doll R, Peto R, Hall E, Wheatley K, Gray R. Mortality in relation to consumption of alcohol: 13 years' observations on male British doctors. BMJ. 1994; 309:911-918. [PubMed: 7950661]

54. Rehm J, Greenfield TK, Rogers JD. Average volume of alcohol consumption, patterns of drinking, and all-cause mortality: results from the U.S. National Alcohol Survey. Am J Epidemiol. 2001; 153:64-71. [PubMed: 11159148]

55. Fuchs CS, Stampfer MJ, Colditz GA, Giovannucci EL, Manson JE, et al. Alcohol consumption and mortality among women. N Engl J Med. 1995; 332:1245-1250. [PubMed: 7708067]

56. Thun MJ, Peto R, Lopez AD, et al. Alcohol consumption and mortality among middle-aged and elderly U.S. adults. N Engl JMed. 1997; 337:1705-1714. [PubMed: 9392695] 
57. Yuan JM, Ross RK, Gao YT, Henderson BE, Yu MC. Follow up study of moderate alcohol intake and mortality among middle aged men in Shanghai, China. BMJ. 1997; 314:18-23. [PubMed: 9001474]

58. Suh I, Shaten BJ, Cutler JA, Kuller LH. Alcohol use and mortality from coronary heart disease: the role of high-density lipoprotein cholesterol: the Multiple Risk Factor Intervention Trial Research Group. Ann Intern Med. 1992; 116:881-887. [PubMed: 1580443]

59. Diehl AK, Fuller JH, Mattock MB, Salter AM, el-Gohari R, et al. The relationship of high density lipoprotein subfractions to alcohol consumption, other lifestyle factors, and coronary heart disease. Atherosclerosis. 1988; 69:145-153. [PubMed: 3348837]

60. Renaud SC, Beswick AD, Fehily AM, Sharp DS, Elwood PC. Alcohol and platelet aggregation: the Caerphilly Prospective Heart Disease Study. Am J Clin Nutr. 1992; 55:1012-1017. [PubMed: 1570795]

61. Corrao G, Bagnardi V, Zambon A, La Vecchia C. A meta-analysis of alcohol consumption and the risk of 15 diseases. Prev Med. 2004; 38:613-619. [PubMed: 15066364]

62. Yuan JM, Ross RK, Gao YT, Qu YH, Chu XD, et al. Prediagnostic levels of serum micronutrients in relation to risk of gastric cancer in Shanghai, China. Cancer Epidemiol Biomarkers Prev. 2004; 13:1772-1780. [PubMed: 15533906]

63. Tolstrup J, Jensen MK, Tjonneland A, Overvad K, Mukamal KJ, et al. Prospective study of alcohol drinking patterns and coronary heart disease in women and men. BMJ. 2006; 332:1244-1248. [PubMed: 16672312]

64. World Health Organization. International Histological classification of Tumors. Vol. No 19. Geneva, Switzerland: World Health Organization; 1978. Histological typing of upper respiratory tract tumors.

65. Licitra L, Bernier J, Cvitkovic E, et al. Cancer of the nasopharynx. Crit Rev Oncol Hematol. 2003; 45:199-213. [PubMed: 12604130]

66. Junker AK, Bonilla FA, Sullivan KE. How to flee the flu. Clin Immunol. 2004; 112:219-220. [PubMed: 15308112]

67. Kangro HO, Osman HK, Lau YL, Heath RB, Yeung CY, et al. Seroprevalence of antibodies to human herpes viruses in England and Hong Kong. J Med Virol. 1994; 43:91-96. [PubMed: 8083655]

68. Hashibe M, Brennan P, Benhamou S, Castellsague X, Chen C, et al. Alcohol drinking in never users of tobacco, cigarette smoking in never drinkers, and the risk of head and neck cancer: pooled analysis in the International Head and Neck Cancer Epidemiology Consortium. J Natl Cancer Inst. 2007; 99:777-789. [PubMed: 17505073] 


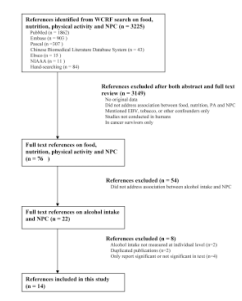

FIG. 1.

Flow diagram of study selection process. 


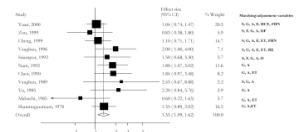

FIG. 2.

Forest plot of OR and 95\% confidence intervals for highest versus lowest category of total alcohol intake and NPC. Results are from a random-effects model. Matching/adjustment variable abbreviations: S, smoking; F, salted fish; G, gender; A, age; E, education; ET, ethnicity; RE, residence; O, occupational exposure; FHN, Family history of NPC; HCE, history of chronic ear and nose disease; OF, other food. 


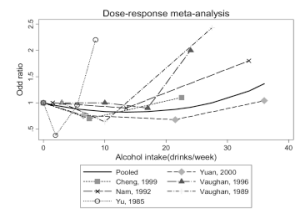

FIG. 3.

Dose-response meta-analysis of case-control study results of NPC risk in relation to total alcohol intake (shown by first author and year of publications). The pooled dose-response curve (thick solid line) was obtained by a quadratic model using generalized least squares for trend estimation. 


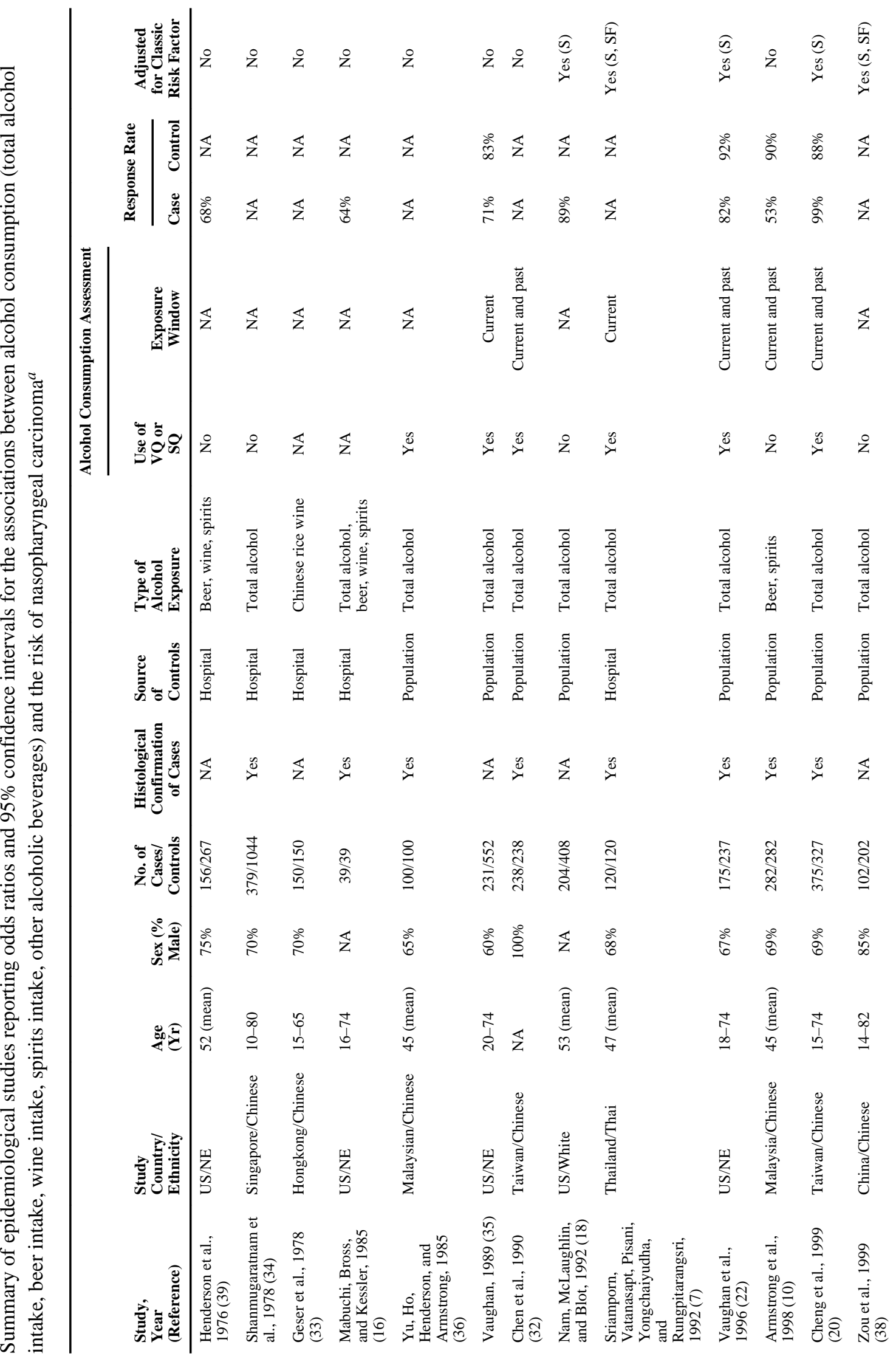




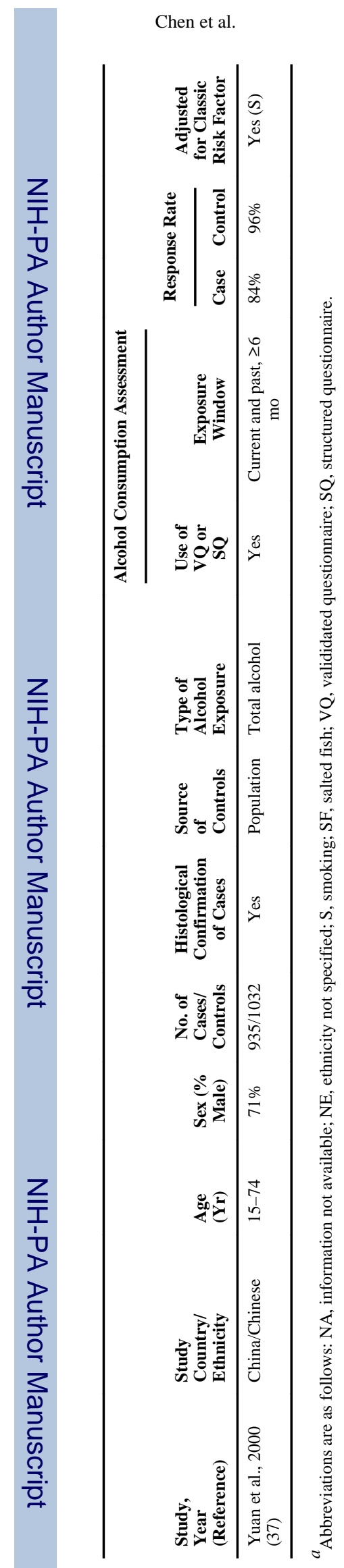

Page 17 


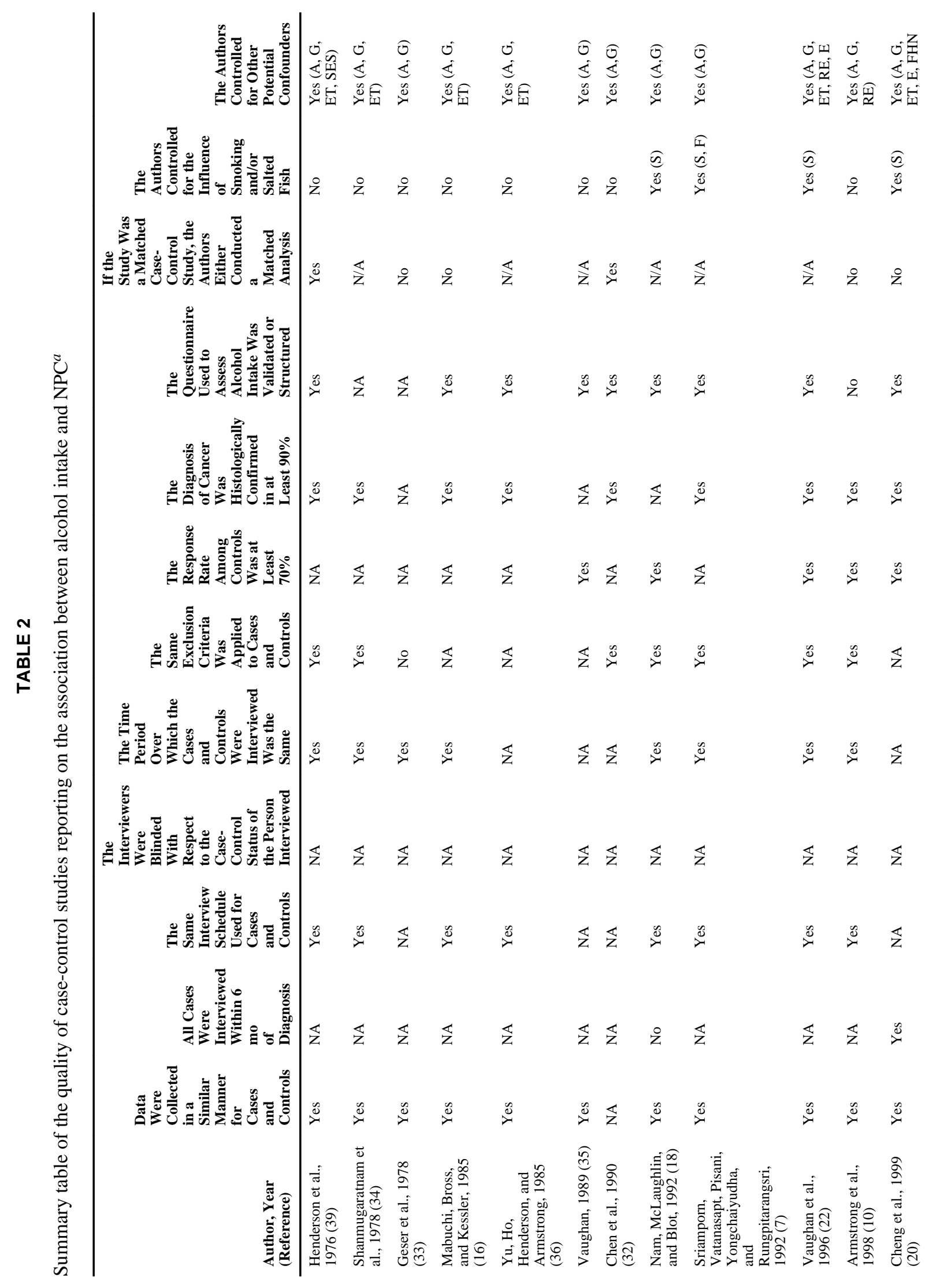

Nutr Cancer. Author manuscript; available in PMC 2011 April 8. 


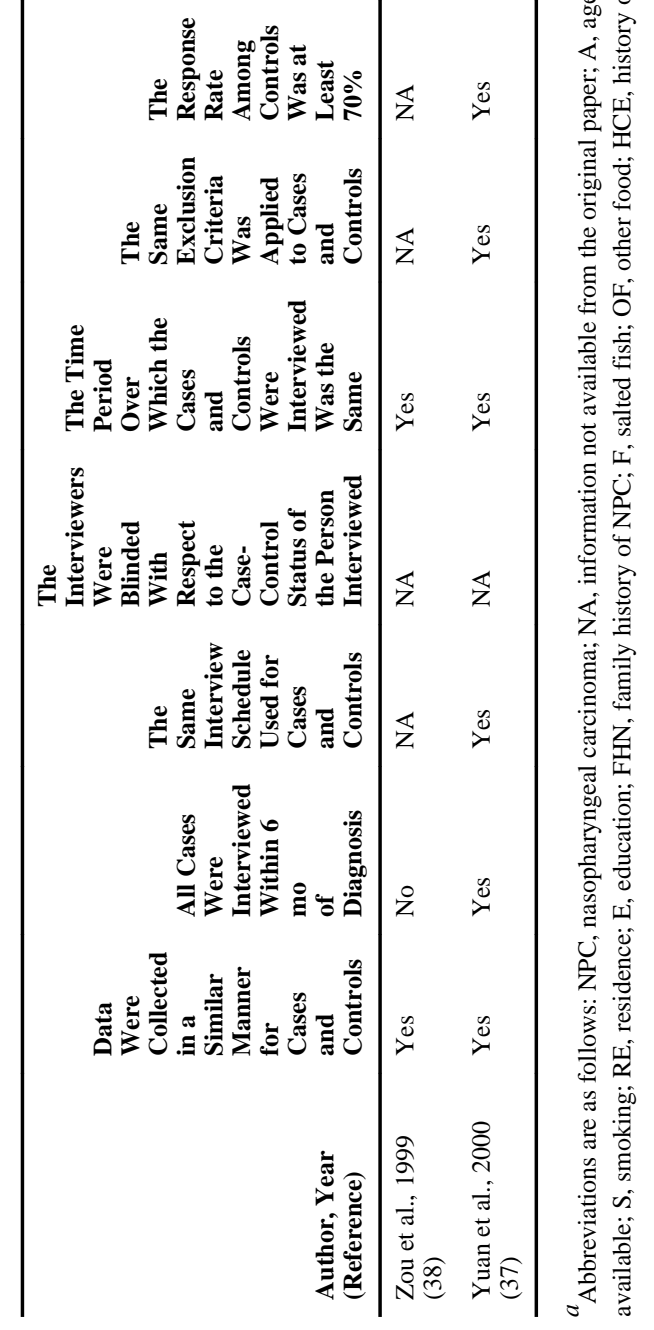




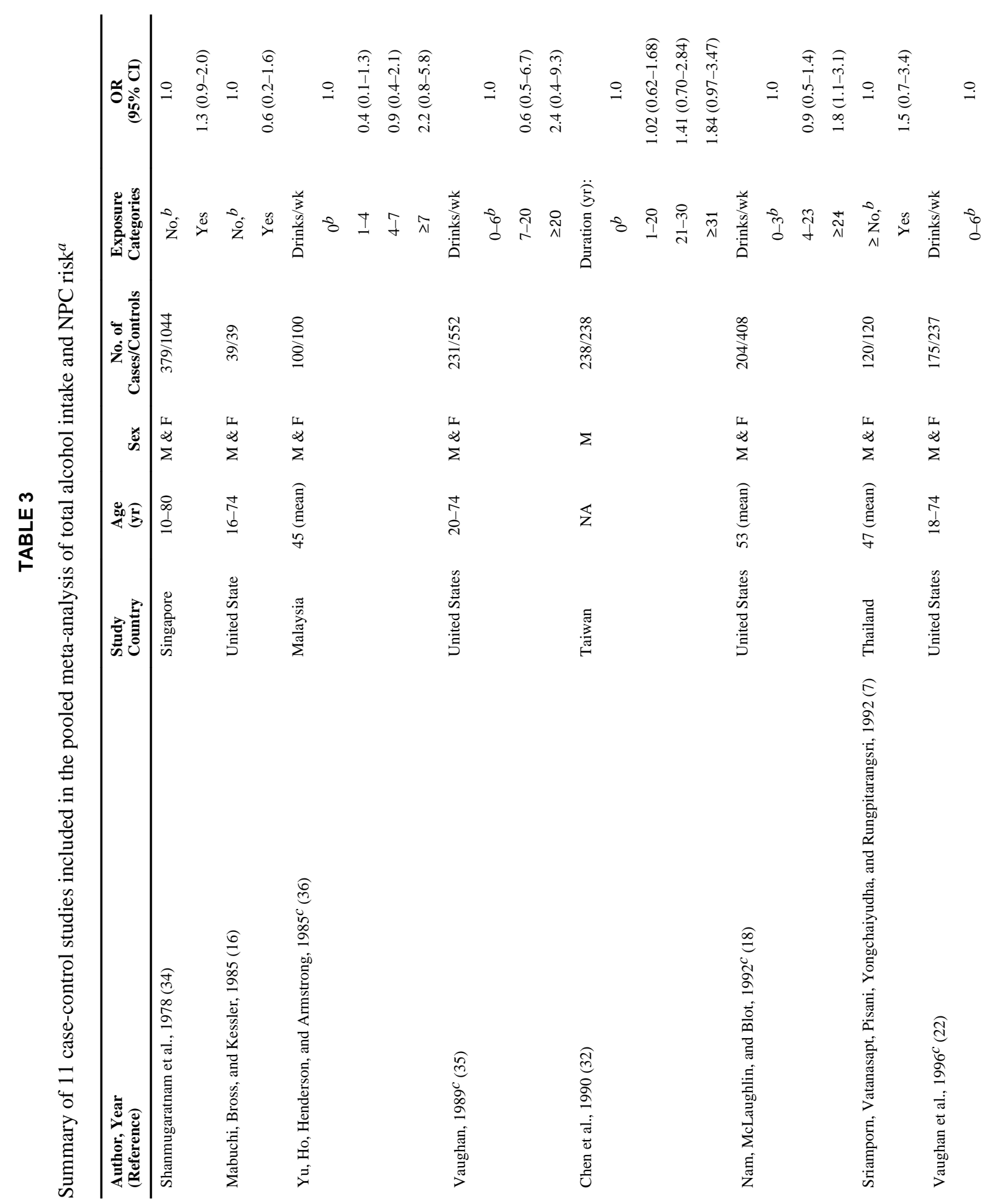


Chen et al.

Page 21

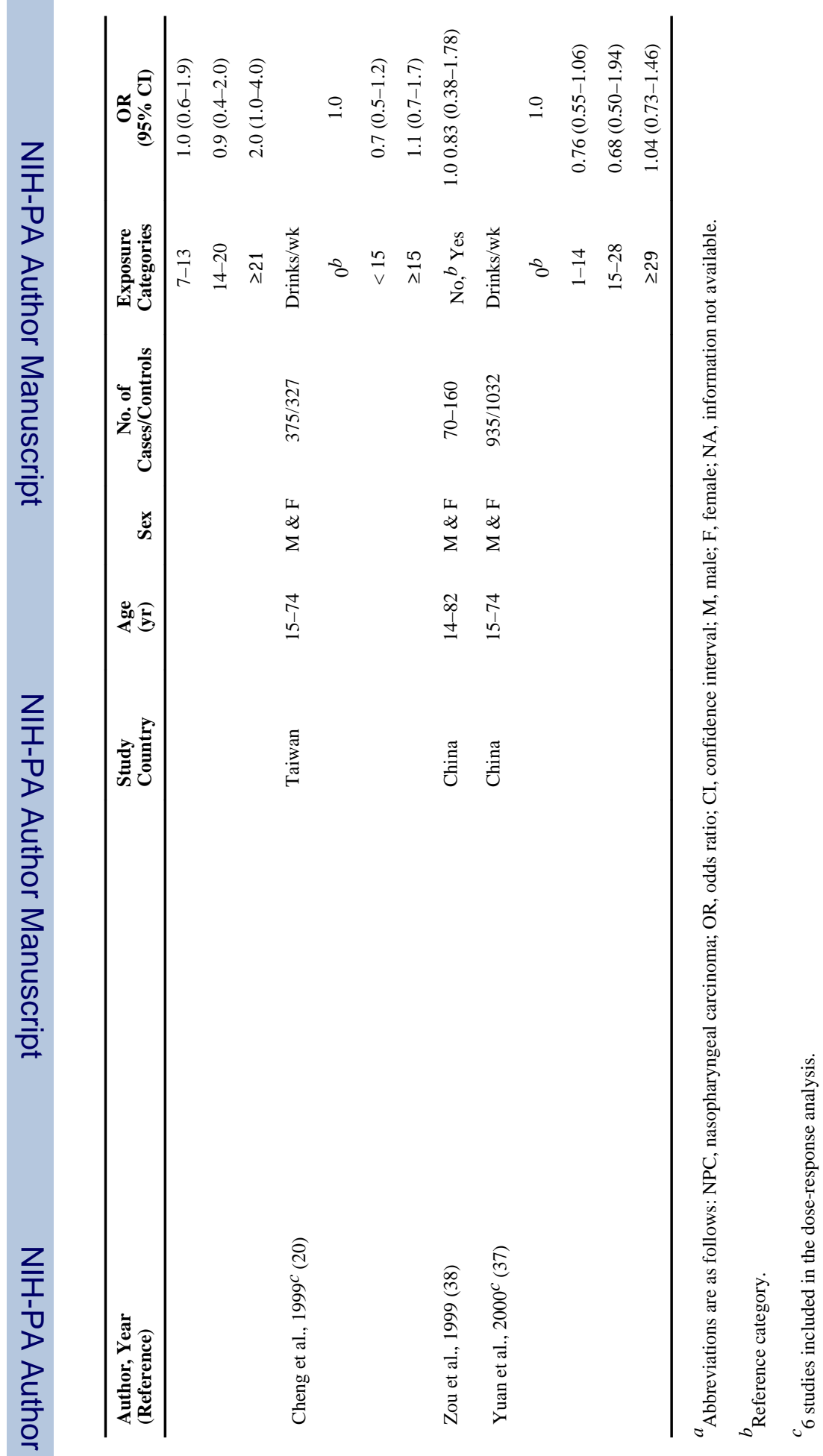

Nutr Cancer. Author manuscript; available in PMC 2011 April 8. 


\section{TABLE 4}

Summary of case-control studies of the association between intake of beer, wine, spirits, Chinese rice wine, and risk of $\mathrm{NPC}^{a}$

\begin{tabular}{|c|c|c|c|c|}
\hline Categories & Study, Year (Reference) & Study Country & Exposure & OR (CI or $P$ Value) \\
\hline \multirow[t]{7}{*}{ Beer } & Henderson et al., 1976 (39) & United States & $\mathrm{No}^{b}$ & 1.0 \\
\hline & & & Yes & $1.0(P=0.48)$ \\
\hline & Mabuchi, Bross, and Kessler, 1985 (16) & United States & $\mathrm{No}^{b}$ & 1.0 \\
\hline & & & Yes & $0.89(0.35-2.25)$ \\
\hline & Armstrong et al., 1998 (10) & Malaysia & Low $b$ & 1.0 \\
\hline & & & Medium & $1.95(1.18-3.22)$ \\
\hline & & & High & $2.50(1.44-4.45)$ \\
\hline \multirow[t]{4}{*}{ Wine } & Henderson et al., 1976 (39) & United States & $\mathrm{No}^{b}$ & 1.0 \\
\hline & & & Yes & $0.7(P=0.05)$ \\
\hline & Mabuchi, Bross, and Kessler, 1985 (16) & United States & $\mathrm{No}^{b}$ & 1.0 \\
\hline & & & Yes & $0.58(0.23-1.46)$ \\
\hline \multirow[t]{7}{*}{ Spirits } & Henderson et al., 1976 (39) & United States & $\mathrm{No}^{b}$ & 1.0 \\
\hline & & & Yes & $1.2(P=0.31)$ \\
\hline & Mabuchi, Bross, and Kessler, 1985 (16) & United States & $\mathrm{No}^{b}$ & 1.0 \\
\hline & & & Yes & $0.35(0.12-1.0)$ \\
\hline & Armstrong et al., 1998 (10) & Malaysia & Low $b$ & 1.0 \\
\hline & & & Medium & $1.28(0.74-2.22)$ \\
\hline & & & High & $2.92(1.05-8.14)$ \\
\hline \multirow[t]{2}{*}{ Chinese rice wine } & Geser et al., 1978 (33) & China/Hong Kong & $\mathrm{No}^{b}$ & 1.0 \\
\hline & & & Yes & $0.56(0.35-0.90)$ \\
\hline
\end{tabular}

${ }^{a}$ Abbreviations are as follows: NPC, nasopharyngeal carcinoma; OR, odds ratio; CI, confidence interval.

${ }^{b}$ Reference group. 